This is an electronic reprint of the original article. This reprint may differ from the original in pagination and typographic detail.

Author(s): Nikula, Tarja

Title: $\quad$ Emerging themes, future research directions

Year: $\quad 2017$

Version:

Please cite the original version:

Nikula, T. (2017). Emerging themes, future research directions. In A. Llinares, \& T.

Morton (Eds.), Applied Linguistics Perspectives on CLIL (pp. 307-312). John

Benjamins. Language Learning and Language Teaching, 47.

https://doi.org/10.1075/IIlt.47.18nik

All material supplied via JYX is protected by copyright and other intellectual property rights, and duplication or sale of all or part of any of the repository collections is not permitted, except that material may be duplicated by you for your research use or educational purposes in electronic or print form. You must obtain permission for any other use. Electronic or print copies may not be offered, whether for sale or otherwise to anyone who is not an authorised user. 


\section{AFTERWORD: EMERGING THEMES, FUTURE RESEARCH DIRECTIONS}

Tarja Nikula

As CLIL research has expanded over the last couple of decades, an emerging issue has been the complexities involved, especially due to the often very different forms of CLIL implementation across contexts. This volume offers a different orientation to complexity as it brings together applied linguistic research orientations to CLIL that have earlier usually been treated separately in the research literature, namely second language acquisition (SLA), systemic functional linguistics (SFL), as well as discourse analytic and sociolinguistic perspectives.

The four orientations offer different entry points and foci of analysis. Firstly, the purpose of SLA research is to query aspects of language learning and teaching in content-based teaching. In his introductory chapter, Lyster highlights this from the viewpoint of counterbalanced approach which acknowledges the need for explicit language orientation alongside content focus in content-based scenarios. The three chapters that follow address different aspects of SLA research each: the importance of the interactionist approach in exploring language learning (Garcia Mayo and Basterrechea); the role of motivation in CLIL (Sylvén); the impact of CLIL on learners' pragmatic competence (Nashaat). In the second section, Coffin describes SFL in her introductory chapter as a theory of language as meaning, and the different meaningmaking mechanisms at ideational, interpersonal and textual levels. Coffin argues that a key asset of SFL is "to explain and make visible the linguistic dimensions of subject content and the role of language in teaching-learning processes". The chapters in this 
section explore the following aspects of teaching-learning processes: speech functions/exchange structures in different activity types and their impact on role assignment and on learners' ability to construe field knowledge of history (Llinares and Morton); appraisal resources as an indication of CLIL students' development in writing (McCabe and Whittaker); the role of multi-semiotic resources in scaffolding science class learners towards disciplinary literacy (Forey and Polias). Thirdly, discourse analysis operates at the level of enacted practice, paying attention to how language use both constructs and reflects contexts. As Dalton-Puffer argues in her introductory chapter, an important aim for research in this area is to unravel the nature of CLIL classrooms as a context of learning and of language use. The three chapters in this section address classroom interactional competence and learning as a collective and reciprocated undertaking (Escobar and Walsh); the importance of multisemiotic resources for meaning-making and learning as participants' joint accomplishment (Evnitskaya and Jakonen); the role of meta-questions in assessing and reflecting on learning as part of assessment for learning practices (Pascual and Basse). Fourthly, sociolinguistic orientations adhere to the broader societal dimensions pertaining, for example, to the role of languages, stakeholder beliefs and identities in relation to languages as argued by Cenoz who also highlights the idea of CLIL as an educational programme rather than a foreign language teaching approach. The three chapters in this section deal with the following topics: CLIL teachers' knowledge structures and identity aspects and their impact on rationales of CLIL (Bonnet and Breidbach); teachers' conceptions of the role of L1 in their CLIL practice (Lasagabaster); the multifaceted roles of English in English-medium instruction at university level as a social and discursively constructed phenomenon (Dafouz and Smit). 
As the above brief overview shows, the present volume offers a versatile look into the state-of-the art in current CLIL research as it is advancing into its third decade. The book provides clear evidence of how the field has developed from the early phases when the emphasis was largely on outcome-oriented studies and descriptive accounts of CLIL programmes (Dalton-Puffer, Nikula \& Smit 2010: 8-11) to a set of versatile research orientations that are well suited to address the multidimensionality inherent in any educational programme. While the four research orientations have their own emphases and theoretical and methodological underpinnings, a strength of the volume is that it also brings forth points of convergence across different areas. Such shared concerns are important for moving from fragmented conceptualisations of CLIL toward more coherent ones as well for indicating future research directions. The following discussion will centre on some of the main themes emerging in the volume.

\section{The centrality of interaction}

A prominent theme in the volume is the importance accorded to interaction in CLIL. It is in interaction that processes of teaching and learning take place and it is through studying interaction that a more fine-grained understanding of content and language integration and processes of learning and teaching can be gained. The centrality of interaction is evident in several chapters. Firstly, Garcia Mayo and Basterrechea call for greater use of interactionist framework in the study of language learning in CLIL. They draw attention for example to the important role that the teacher has in implementing successful episodes of negotiation of language forms and in the provision of corrective feedback routines to support language learning. Also Pascual and Basse highlight the 
teachers' role in classroom interaction, this time from the perspective of meta-questions to steer learners towards assessing learning and engaging in its meta-cognitive reflection. Llinares and Morton, for their part, pay attention to the impact of different activity types (interviews vs. role plays) on participants' speech functions and their opportunities to engage in negotiations of content knowledge.

Focus on interaction is also closely connected to the conception of learning as inherently social and action based, as something that participants do and accomplish rather than 'possess'. Seen this way, learning also needs to be understood as a collective rather than an individual undertaking, i.e. rather than being a context for learning, interaction constitutes learning. This orientation plays out clearly in the chapter by Escobar and Walsh as they focus on the notion of classroom interactional competence and its role in mediating and assisting both content and language learning. Another inherently interactional approach to CLIL is presented by Evniskaya and Jakonen, who outline a conversation analytic approach to learning and highlight how CA-for-SLA research sees learning as joint interactional accomplishment.

A further dimension emerging in the volume is the importance accorded to interaction as a multisemiotic endeavour, dependent in addition to language also on a rich array of other modalities, ranging from movements and gaze to the use of artefacts. The two chapters mentioned above, Escobar and Walsh as well as Evnitskaya and Jakonen, are examples of multimodal conversation analyses on CLIL classrooms. In addition, Forey and Polias outline an orientation that places emphasis on the use of multisemiotic resources in science classrooms in the learning of disciplinary literacy, arguing that by utilising different modalities, teachers can provide 'multiple access points to meaning' for learners and thus scaffold learning. 


\section{Reconceptualising the role of language in CLIL}

In recent research literature, there have been calls for a better conceptualisation of the content and language relationship in CLIL (e.g. Llinares, Morton \& Whittaker 2012; Nikula, Dafouz, Moore \& Smit 2016). This volume responds to such calls, in particular by highlighting how the language-content double focus of CLIL makes it necessary to reconceptualise what language is in ways that acknowledge the influence of different subject areas. McCabe and Whittaker, for example, when studying CLIL students' development in writing, focus on their mastery of genres specific to history, with special attention to the use of appraisal in indexing the voice of the historian. The importance of scaffolding learners towards subject-specific language patterns is also a core concern in the chapter by Forey and Polias. Llinares and Morton address the issue of field-specific language and knowledge when examining the impact of different activity types and their exchange structures on language use. All the above authors also express the need to make CLIL teachers more aware of the fundamental role of language in all subject learning and knowledge construction (see also Meyer et al. 2015). This does not mean adding a completely new dimension to teachers' skill repertoire. As the chapters by Escobar and Walsh and Evnitskaya and Jakonen indicate, interaction in CLIL classrooms shows several signs of participants subtly orienting to and negotiating both content and language aspects. Awareness-raising thus needs to be oriented towards providing teachers and learners tools to raise their 'language work' to a more explicit level. 


\section{Attention to mindsets: beliefs, identities, motivations}

The volume also argues for the importance of accounting for both learner and teacher beliefs and orientations for a fuller understanding of CLIL. Sylvén approaches the matter from the viewpoint of learners and motivation, discussing in the light of earlier research and developments in motivational theory a range of factors for which CLIL can be seen to offer more motivational possibilities than L2/FL classrooms, pointing out at the same time that more research is needed in this area, especially as regards the longterm motivational impacts. The question of teacher beliefs and conceptions, for its part, is tackled by Bonnet and Breidbach whose case study focuses on teacher knowledge and identity issues. They show how two CLIL teachers working in a similar context draw on very different rationales, displaying a pedagogical versus a disciplinary orientation. This results in different views of learning (as something that can be scaffolded vs as a matter of giftedness) and in differences in agency, ownership and cooperation in CLIL. Lasagabaster's study is also concerned with teacher beliefs, this time concerning their understanding about L1 use in CLIL classrooms. His findings indicate a great deal of variation in teacher orientations to the desirability and usefulness of L1 use. What is common, however, is that L1 use gets constructed mainly as a support strategy motivated by learners' insufficient target language competence rather than as an inherent feature of bilingual discourse. Teacher interviews thus reveal a great deal about language ideologies in CLIL, a point also made clear by Dafouz and Smit who explore university teacher perceptions of the role of English.

\section{The role of English}


An important factor in the growing interest in CLIL is that it is seen as an approach that helps prepare learners for the increasingly international world where English is a major lingua franca. Therefore, an area that would merit more research in the future is the relationship between English language and CLIL. Drawing on Graddol (2006), Sylvén brings up the contention that there may indeed be a need to recontextualise English as a basic skill rather than as a second or foreign language and explore its use as instructional language from that perspective. What the implications of this would be for language learning objectives in CLIL remains an empirical question. Another future research avenue concerns unravelling the discursive and language ideological embedding of CLIL, especially with regard to English. Dafouz and Smit provide an important step to this direction by examining university teachers' discursive constructions of the roles of English, relating them to broader discourses pertaining to societal, institutional, pedagogical and communicational dimensions. They indicate that the role of English needs to be seen as a multidimensional phenomenon, simultaneously firmly situated in broader discourses and ideologies as well as indexing them. Such complexity and multidimensionality calls for research orientations that can acknowledge multi-sited webs of influence (for similar observations, see Halonen, Ihalainen \& Saarinen 2015).

\section{In conclusion}

As this volume shows, the research base on CLIL is robust and aligns with general developments in applied linguistics as regards, for example, the growing emphasis on 
language and learning as social phenomena (for overview, see Atkinson 2011). Areas where CLIL research needs to develop are also identified in the volume. One concerns the need for more longitudinal research designs to complement the predominantly crosssectional research orientations. Secondly, while the volume shows that there is solid ground and good data sets for exploring CLIL as a situated and interactional phenomenon, there is room for ethnographically-oriented research to uncover participant perspectives and CLIL as a lived experience. The volume also exemplifies a varied use of qualitative research methods. The study by Nashaat is the only one combining experimental quantitative and qualitative methods; she succeeds in unravelling tendencies and patterns in the use of learners' modification strategies that would have remained hidden by relying on observational data only. This suggests that also more generally, CLIL research would benefit from a good balance between quantitative and qualitative research designs.

In the first chapter of this volume, Roy Lyster points out that while research progresses, understandings of effective instructional practice keep evolving and that "applied researchers $[\ldots]$ have the potential and even the responsibility to contribute constructively to this evolution". The present volume is an excellent example of such research contribution that will no doubt become a valuable resource for CLIL researchers and practitioners alike.

\section{References}

Atkinson, D. (Ed.). (2011). Alternative approaches to second language acquisition. Abingdon: Routledge 
Dalton-Puffer, C., Nikula, T., \& Smit, U. (2010). Charting policies, premises and research in content and language integrated learning. In C. Dalton-Puffer, T. Nikula \& U. Smit (Eds.). Language use and language learning in CLIL classrooms (pp. 1-19). Amsterdam: John Benjamins.

Graddol, D. (2006). English next. London: The British Council.

Halonen, M., Ihalainen, P., \& Saarinen, T. (2015). Diverse discourses in time and space: historical, discourse analytical and ethnographic approaches to multi-sited language policy discourse. In M. Halonen, P. Ihalainen, \& T. Saarinen (Eds.). Language policies in Finland and Sweden. Interdisciplinary and multi-sited comparisons (pp. 3-26). Bristol: Multingual Matters.

Meyer, O., Coyle, D., Halbach, A., Schuck, K., \& Ting, T. (2015). A pluriliteracies approach to content and language integrated learning - mapping learner progressions in knowledge construction and meaning-making. Language, Culture and Curriculum, 28, 41-57. DOI: 10.1080/07908318.2014.1000924

Llinares, A., Morton, T., \& Whittaker, R. (2012). The roles of language in CLIL. Cambridge: Cambridge University Press.

Nikula, T., Dafouz, E., Moore, P., \& Smit, U. (Eds.) (2016). Conceptualising integration in CLIL and multilingual education. Multilingual Matters. 